Analitika: Jurnal Magister Psikologi UMA, Vol. 13 (2) Desember (2021)

ISSN: 2085-6601 (Print), ISSN: 2502-4590 (Online)

DOI: : http://doi.org/10.31289/analitika.v13i1.5855

\title{
ANALITIKA
}

Jurnal Magister Psikologi UMA

Available online http://ojs.uma.ac.id/index.php/analitika

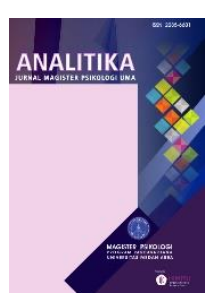

\section{Perbedaan Tipe Faking antara Pelamar Fresh Graduate dengan Berpengalaman pada Wawancara Kerja}

\author{
The Differences of Faking Type \\ between Fresh Graduate with Experienced at Job Interview
}

\author{
Mukhaira El Akmal* \& Diny Atrizka \\ Fakultas Psikologi, Universitas Prima Indonesia, Indonesia
}

Diterima: 17 September 2021, disetujui: 22 Desember 2021, dipublish: 30 Desember 2021

*Corresponding author: E-mail: mukhaira.akmal@gmail.com

\begin{abstract}
Abstrak
Perilaku faking merupakan sesuatu hal yang umum dilakukan oleh pelamar dalam kegiatan wawancara kerja. Namun, faking yang dilakukan oleh pelamar dapat mempengaruhi asesor/interviewer dalam memberikan penilaian yang tepat. Penelitian ini bertujuan untuk menunjukkan gambaran mengenai tipe faking dan melihat perbedaan tipe faking pada pelamar fresh graduate dan berpengalaman pada wawancara kerja. Penelitian ini menggunakan pendekatan kuantitatif dengan desain non-eksperimental kepada 262 orang, yang diseleksi di beberapa perusahaan di Kota Medan. Teknik pengambilan sampling yang digunakan adalah accidental sampling. Penelitian ini menggunakan alat ukur Interview Faking Behavior Scale. Pengujian hipotesis dilakukan dengan menggunakan teknik analisa data T-test. Hipotesis yang diajukan dalam penelitian ini yaitu "terdapat perbedaan tipe faking pada pelamar fresh graduate dan berpengalaman dalam wawancara kerja". Penelitian ini memperlihatkan tidak ada perbedaan tipe faking antara pelamar fresh graduate dan pelamar berpengalaman dalam wawancara kerja berdasarkan hasil analisis data nilai T-hitung $(-1,550)<$ T-tabel $(1,969)$ dengan taraf signifikansi $0,719>0,05$. Selanjutnya nilai F-hitung $(0,130)<$ F-tabel $(1,366)$.

Kata kunci: Faking; Wawancara Kerja; Pelamar Organisasi
\end{abstract}

\begin{abstract}
Faking mechanism is the most common strategy held during the interview. However, it is obviously a main issue during the interview since it is considered as the cause of the discrepancy of an assessment. This study is therefore aimed to elaborate the difference of faking committed by fresh graduate and working-experienced candidates. This research used a quantitative approach with non-experimental design, conducted on 262 respondents, those being selected at the companies in Medan City. Accidental sampling were applied in this research. The measurement tool used is Interview Faking Behaviour Scale. Testing hypotheses was analysed by means of T-test. The proposed hypothesis of the study that there is a difference between the fresh graduate interviewee and their counterparts who already had work experienced during the job interview. Those with fresh graduates and the interview experience has not proven to be different based on the T-test data analysis, T-value $(-1,550)<\mathrm{T}$-table $(1,969)$ with the degree of significance $0,719>0,05$. Furthermore F-value $(0,130)<$ F-table $(1,366)$.
\end{abstract}

Keywords: Faking; Job Interview; Applicant

How to Cite: Akmal, M.E., \& Diny, A. (2021). Perbedaan Tipe Faking antara Pelamar Fresh Graduate dengan Berpengalaman pada Wawancara Kerja. Analitika: Jurnal Magister Psikologi UMA, 13 (2): 117 -126. 


\section{PENDAHULUAN}

Dunia usaha semakin kompetitif, perusahaan dituntut untuk dinamis dan dapat merespon permintaan pasar dengan cepat. Dibutuhkan karyawan handal untuk dapat menjaga dan menjalankan roda organisasi dengan baik. Hal ini dapat diperoleh dengan sistem seleksi karyawan yang dapat memenuhi persyaratan yang dituntut oleh perusahaan baik dari sisi kuantitas maupun kualitas. Seleksi merupakan serangkaian langkah kegiatan yang dilaksanakan untuk memutuskan apakah seorang pelamar diterima atau ditolak, dalam suatu perusahaan (Garaika \& Helisia, 2019; Hamali, 2018; Rivai \& Sagala, 2013; Sunyoto, 2012). Tujuan seleksi sendiri adalah mencocokkan secara benar antara orang dengan pekerjaan. Salah satu metode dalam seleksi yang populer adalah wawancara (interview).

Interview telah diadopsi hampir secara luas dalam membuat keputusan untuk sebuah perekrutan karyawan. Interview seleksi adalah percakapan formal dan mendalam yang dilakukan untuk mengevaluasi apakah seorang kandidat dapat diterima atau tidak (acceptability) sebagai karyawan. Interview lebih dari sekedar bertanya dan menjawab suatu pertanyaan. Interviewer mencari jawaban atas dua pertanyaan umum mengenai apakah pelamar dapat melaksanakan pekerjaannya, dan bagaimanakah kemampuan pelamar dibandingkan dengan pelamar lain (Bloomfield, et al., 2006). Dengan kriteria yang ditetapkan, interview dalam proses seleksi menilai pendidikan, pelatihan, pengalaman, prestasi, kemampuan, dan karakteristik pribadi pelamar atau menilai karakteristik organisasi, sifat posisi, harapan, lokasi, manfaat, dan potensi untuk kemajuan (Stewart \& Cash, 2003).

Menurut Bloomfield, Schofield, \& Cantesbury (2006), interview memiliki 2 fungsi seleksi yang penting: (1) Interview memungkinkan penyeleksi bertemu dengan pelamar dan memungkinkannya untuk mengubah bayangan statis mengenai diri pelamar yang terbentuk setelah membaca dan mempelajari formulir-formulir lamaran kerja dan hasilhasil tes. Interview juga memberikan wawasan mengenai perilaku masa lalu dari pelamar kerja dan dasar-dasar alasannya. Dalam kerangka penentuan spesifikasi personil, interview berguna untuk menaksir motivasi dan disposisi. Namun interview kurang berguna dalam wilayah-wilayah kecerdasan dan kinerja actual yang lebih akurat dinilai jika menggunakan tes-tes yang dirancang secara tepat; (2) Interview berfungsi sebagai sebuah mekanisme self-selection yang berguna. Interview memberikan kesempatan kepada pelamar untuk mengetahui bagaimana perusahaan yang hendak dimasukinya. Pelamar berbicara dengan wakil dari perusahaan, mengetahui bagaimana persisnya pekerjaan yang ditawarkan, dan memutuskan apakah ia memiliki kecocokan dengan perusahaan tersebut.

Evaluasi interview terdiri dari dua bagian: satu set pertanyaan standar dan satu set pertanyaan terbuka. Bagian pertanyaan standar terdiri dari kualifikasi pekerjaan yang bonafit untuk setiap posisi dan memungkinkan penentuan seberapa sesuai pelamar dengan kualifikasi yang dipersyaratkan. Evaluasi terhadap hasil interview pelamar tidak selalu berjalan lancar. Ada saja faktor-faktor yang dapat menghambat keberhasilan dalam suatu interview, salah satunya adalah interview faking yang dilakukan oleh pelamar. 
Teknik interview penting dilakukan dalam proses seleksi karena efektivitasnya dapat dipercaya dan mempunyai fleksibilitas (Reddy, 2016). Namun demikian mengandalkan teknik interview bukannya tanpa hambatan. Salah satu potensi yang menghambat keberhasilan dalam suatu interview adalah manajemen kesan atau dapat disebut sebagai impression management. Secara eksplisit, impression management tersebut dapat digambarkan sebagai sebuah interview faking. Menurut Levashina dan Campion (2007) interview faking merupakan distorsi yang disengaja mengenai sebuah jawaban dengan tujuan untuk mendapatkan nilai yang terbaik ketika wawancara atau mungkin membentuk suatu persepsi yang baik.

Goffin dan Boyd (dalam Pita, 2011) menyatakan bahwa perilaku faking pada kandidat secara garis besar didefenisikan sebagai sebuah tindakan menipu yang cenderung dapat menciptakan sebuah kesan yang baik. Perilaku faking (menipu) yang dilakukan oleh seorang pelamar pekerjaan (applicant faking behavior) merupakan istilah untuk semua perilaku yang dilakukan oleh pelamar pekerjaan selama prosedur penyeleksian karyawaan yang mengandung respon intensional dalam mengukur kepribadian individu itu sendiri tetapi tidak mengandung identitas diri yang sebenarnya. Pengertian tersebut dapat menjelaskan beberapa pengertian penting. Pertama, faking dideskripsikan sebagai sebuah perilaku dan bukan sebagai sebuah sifat jika berdasarkan pengertian sebelumnya. Kedua, perilaku dideskripsikan sebagai sebuah intensional yang secara jelas berasal dari kesalahan yang kacau dan penyimpangan yang tidak sistematik lainnya. Ketiga, berdasarkan pencocokan dengan identitias diri yang sebenarnya, pengertian tersebut tidak memiliki asumsi pada pengertian yang mengarah kepada penyimpangan.

Menurut Kiefer dan Benit (2016), motivasi dan kemampuan menipu atau fake merupakan pusat pengaruh dalam perilaku menipu. Untuk melakukan penipuan tersebut harus memiliki keinginan serta kemampuan untuk melakukan hal tersebut. Kerangka teoritis menyatakan bahwa seorang pelamar yang sedang membutuhkan pekerjaan baru yang mempercayai bahwa faking sangat diperlukan untuk mendapatkan sebuah pekerjaan, merupakan sebuah motivasi yang kuat untuk calon karyawan tersebut untuk melakukan faking. Motivasi juga dapat berasal dari kontrol diri (self-monitoring) serta efikasi diri (self-eficacy). Kemampuan mental yang secara umum seperti kecerdasan emotional atau empati, keduanya memainkan peran dalam kemampuan menipu atau fake. Yu (2008) menambahkan tingkat kesungguhan hati yang dimiliki oleh seseorang biasanya dapat menjadi perilaku yang mendahului dalam faking dan intelegensi memainkan peran tambahan bagi individu yang mampu untuk memaksimalkan nilai tes.

Krauss mendefenisikan faking (menipu) sebagai sebuah tindakan yang dimaksudkan untuk menumbuhkan rasa percaya atau pengertian terhadap orang lain ketika penipu tersebut sedang dianggap melakukan kesalahan. Pengertian ini menunjukkan bahwa menipu adalah sebuah tindakan (apakah hal tersebut berupa perkataan maupun tindakan) dan cenderung membentuk sebuah kepercayaan atau pengertian yang salah. Sementara, Mitchell menyatakan bahwa faking (menipu) merupakan sebuah komunikasi yang keliru sehingga cenderung menguntungkan komunikator. Ekman mendefenisikan 
faking sebagai suatu pilihan yang disengaja untuk memperdaya sebuah target tanpa memberikan pemberitahuan apapun mengenai maksud tersebut. Faking yang dilakukan oleh seorang pelamar pekerjaan secara sadar dalam mengaburkan representasi diri pelamar itu sendiri untuk menciptakan sebuah kesan yang baik ketika sedang melakukan pengukuran kepribadian (dalam Pita, 2011).

Levashina dan Campion (2007) mengembangkan sebuah pengukuran melalui 4 model faktor mengenai impression management yang digunakan dalam interview yang meliputi: (1) Slight image creation, usaha kecil dalam melakukan faking untuk menciptakan kesan yang baik bagi kandidat, seperti menceritakan pengalaman kerja secara berlebihan; (2) Extensive image creation, perilaku menipu yang ekstrim, seperti menciptakan pengalaman kerja yang pada kenyataannya tidak pernah dimiliki oleh calon karyawan tersebut; (3) Image protection, usaha untuk membela diri, seperti mengabaikan pengalaman kerja yang buruk yang dilakukan oleh pelamar tersebut; dan (4) Deceptive ingratiation, usaha yang dilakukan agar calon karyawan tersebut disukai, seperti memuji interviewer seakan-akan dengan tulus hati. Levashina dan Campion (2007) mengembangkan 3 faktor yang memungkinkan bagi seorang pelamar melakukan perilaku ketika sedang berlangsungnya interview, yaitu (a) capacity-sebuah kemampuan untuk menciptakan respon yang menyimpang; (b) willingness-suatu motivasi atau kecenderungan untuk menciptakan respon yang menyimpang; dan (c) opportunity-suatu situasi yang mempengaruhi respon yang menyimpang. Selain itu, terdapat dua tipe perilaku menipu dari seorang pelamar kerja yang digabungkan secara empiris dan teoritis yang biasanya dikenal sebagai slight faking dan extreme faking. Salah satu perbedaan yang utama dari slight faking dengan extreme faking adalah bagaimana seorang pelamar memposisikan diri mereka antara gambar diri yang murni dan identitas yang ideal (Kiefer dan Benit, 2016).

Mengacu pada penelitian-penelitian sebelumnya, peneliti tertarik untuk mendalami lebih jauh mengenai tipe faking yang digunakan oleh pelamar fresgraduate dan pelamar berpengalaman dalam wawancara kerja. Penelitian ini diharapkan dapat memberikan gambaran mengenai perilaku interview faking yang dilakukan pelamar pada kegiatan seleksi karyawan. Hal ini dikarenakan upaya faking yang dilakukan pelamar mempengaruhi ketepatan asesor dalam memberikan penilaian saat seleksi, sehingga pada akhirnya akan merugikan perusahaan baik secara finansial maupun moril. Penelitian ini diharapkan juga dapat menjadi langkah awal peneliti untuk menghasilkan rancangan modul wawancara yang berguna untuk meminimalisir upaya faking yang dilakukan pelamar saat mengikuti kegiatan seleksi di perusahaan.

\section{METODE PENELITIAN}

Penelitian ini merupakan penelitian kuantitatif dengan desain non-eksperimental. Tujuan penelitian ini adalah untuk menunjukkan gambaran mengenai tipe faking dan melihat perbedaan tipe faking pada pelamar fresh graduate dan berpengalaman pada wawancara kerja. Target subjek penelitian ini sebanyak 300 orang dengan kriteria sebagai berikut: (1) Kandidat yang mengikuti kegiatan seleksi karyawan di Perusahaan di Kota 
Medan; (2) Memiliki pengalaman/fresh graduate; dan (3) Bersedia menjadi subjek penelitian. Teknik pengambilan sampel yang digunakan adalah accidental sampling, ketika orang yang kebetulan ditemui cocok sebagai sampel, maka peneliti dapat menggunakannya sebagai subjek penelitian (Sugiyono, 2016). Kemudian, dari 300 kuesioner yang disebarkan, diperoleh 262 orang sebagai subjek penelitian. Dengan demikian, response rate yang diperoleh sebanyak 86\%. Penelitian ini menggunakan Interview Faking Behavior Scale yang disusun oleh Levashina dan Campion (2007) sebanyak 64 aitem. Aitem-aitem dalam Interview Faking Behavior Scale ini terdiri dari 4 faktor (Slight Image Creation, Extensive Image Creation, Image Protection, dan Ingratiation) dan 11 subfaktor (Embellishing, Tailoring, Fit Enhancing, Constructing, Inventing, Borrowing, Masking, Distancing, Omitting, Conforming, and Interviewer Enhancing). Model skala yang digunakan adalah model skala likert, peneliti memodifikasi dengan menggunakan lima respon jawaban, yaitu sangat sering, sering, kadang-kadang, jarang, dan tidak pernah.

Selain itu, penelitian ini merupakan lanjutan dari penelitian yang dilakukan oleh peneliti sebelumnya. Penelitian terdahulu menunjukkan bahwa gambaran self-awareness dan perilaku faking diperlihatkan dalam beberapa aspek yang berbeda (Akmal, et al., 2021). Tipe faking yang paling sering ditunjukkan oleh kandidat dalam penelitian ini adalah tipe Slight Image Creation dan tipe perilaku faking yang paling jarang ditunjukkan adalah Ingratiation. (Akmal, et al., 2020). Dalam penelitian ini, uji persyaratan analisa yang digunakan adalah uji normalitas dan homogenitas. Teknik analisa data yang digunakan untuk menunjukkan perbedaan tipe faking pada pelamar fresh graduate dan berpengalaman pada wawancara kerja, yaitu Uji Independent Sample T-test.

\section{HASIL DAN PEMBAHASAN}

Berdasarkan 262 data yang diperoleh sebagai subjek penelitian, Hasil pengadministrasian menunjukkan bahwa data yang layak dan memenuhi persyaratan untuk pengolahan data yaitu sebanyak 258. Deskripsi mengenai tipe faking terhadap pelamar fresh graduate dan berpengalaman dapat dilihat pada tabel 1 berikut:

Tabel 1.

Mean Tipe Faking terhadap Pelamar Fresh Graduate dan Berpengalaman pada Wawancara Kerja

\begin{tabular}{cccc}
\hline & N & Mean & SD \\
\hline Fresh Graduate & 63 & 109.22 & 33.611 \\
\hline Berpengalaman & 195 & 116.25 & 30.514 \\
\hline
\end{tabular}

Dari Tabel 1 terlihat bahwa dari jumlah keseluruhan subjek yang berjumlah 258 subjek, diperoleh total pelamar fresh graduate sebanyak 63 orang dan pelamar berpengalaman sebanyak 195 orang. Dari Tabel di atas dapat juga diketahui rata-rata sampel fresh graduate sebesar 109.22, nilai deviasi standar sebesar 33.611, sedangkan nilai rata-rata sampel berpengalaman sebesar 116.25 dan deviasi standar sebesar 30.514 . Hal ini berarti data yang digunakan pada penelitian ini terdistribusi secara normal. 
Mukhaira El Akmal \& Diny Atrizka, Perbedaan Tipe Faking

Antara Pelamar Fresh Graduate dengan Berpengalaman pada Wawancara Kerja

Selanjutnya, deskripsi statistik mengenai perbandingan tipe faking terhadap pelamar fresh graduate dan berpengalaman dapat dilihat pada tabel 2 berikut:

Tabel 2.

Deskripsi Statistik Tipe Faking terhadap Pelamar Fresh Graduate dan Berpengalaman pada Wawancara Kerja

\begin{tabular}{cccccccccc}
\hline & \multirow{2}{*}{ N } & \multicolumn{4}{c}{ Hipotetik } & \multicolumn{4}{c}{ Empirik } \\
\cline { 2 - 10 } & & Min & Max & $\boldsymbol{M}$ & SD & Min & Max & $\boldsymbol{M}$ & SD \\
\hline EIC & 55 & 14 & 70 & 42 & 9.3 & 18 & 70 & 34.07 & 11.182 \\
\hline IP & 162 & 14 & 70 & 42 & 9.3 & 14 & 66 & 34.96 & 9.439 \\
\hline I & 20 & 10 & 50 & 30 & 6.6 & 22 & 44 & 33.75 & 6.189 \\
\hline SIC & 21 & 11 & 55 & 33 & 7.3 & 20 & 46 & 32.33 & 6.636
\end{tabular}

${ }^{*}$ Ket $:$ EIC = Extensive Image Creation; $\mathrm{IP}=$ Image Protection $; \mathrm{I}=$ Ingratiation; $\mathrm{SIC}=$ Slight Image Creation

Berdasarkan perolehan data, diketahui tipe faking Image Protection (IP) merupakan tipe faking yang paling banyak ditampilkan saat wawancara kerja baik oleh pelamar fresh graduate maupun berpengalaman ( $\mathrm{N}=162)$. Tipe faking Extensive Image Creation (EIC) memiliki mean empirik $(M=34,07$ dan $S D=11,182)<$ mean hipotetik $(M=42, S D=9,3)$, Image Protection (IP) yang memiliki mean empirik $(\mathrm{M}=34,96$ dan $\mathrm{SD}=9,439)<$ mean hipotetik (M = 42, SD =9,3), dan Slight Image Creation (SIC) memiliki mean empirik (M = 32,33 dan $\mathrm{SD}=6,636)<$ mean hipotetik $(\mathrm{M}=33, \mathrm{SD}=7,3)$ menunjukkan bahwa secara umum nilai tipe faking Extensive Image Creation (EIC), Image Protection (IP), dan Slight Image Creation (SIC) lebih rendah daripada yang diperkirakan skala. Sebaliknya, data tipe faking Ingratiation (I) memiliki mean empirik $(\mathrm{M}=33,75)$ dan $\mathrm{SD}=6,189)>$ mean hipotetik $(M=30, S D=6,6)$ yang menunjukkan bahwa secara umum tipe faking Ingratiation (I) lebih tinggi daripada yang diperkirakan.

Pengujian hipotesis dilakukan dengan t-test. Persyaratan yang harus dipenuhi yakni data harus normal dan homogen. Berdasarkan pengolahan data dengan KolmogorovSmirnov Test, diperoleh hasil uji normalitas pada tabel 3, sesuai dengan kriteria pengujian sig > 0,05, maka HO diterima yang artinya distribusi frekuensi data yang diuji adalah normal.

Tabel 3

Hasil Uji Normalitas Data Tipe Faking

terhadap Pelamar Fresh Graduate dengan Berpengalaman pada Wawancara Kerja

\begin{tabular}{ccc}
\hline & \multicolumn{2}{c}{ One Sample Kolmogorov-Smirnov } \\
Test
\end{tabular}

Selanjutnya pengujian homogenitas data untuk variabel data tipe faking terhadap pelamar fresh graduate dan berpengalaman dapat dilihat pada tabel 4 . 
Hasil Uji Homogenitas Data Tipe Faking

terhadap Pelamar Fresh Graduate dan Berpengalaman pada Wawancara Kerja

\begin{tabular}{cccc}
\hline $\begin{array}{c}\text { Levene's Test for } \\
\text { Equality of Variances }\end{array}$ & df1 & df2 & Sig. \\
\hline .130 & 1 & 256 & .719 \\
\hline
\end{tabular}

Berdasarkan hasil perhitungan tabel di atas diperoleh nilai signifikansi $\mathrm{p}>0.05$ ( $\mathrm{p}=$ 0.719) menunjukkan bahwa data tipe faking berdasarkan pengalaman atau belum berpengalaman dalam wawancara mempunyai varian sama atau bersifat homogen. Pengujian hipotesis dilakukan dengan menggunakan teknik analisa data T-test. Hipotesis yang diajukan dalam penelitian ini yaitu "terdapat perbedaan tipe faking terhadap pelamar fresh graduate dan berpengalaman pada wawancara kerja". Hasil pengujian terhadap hipotesis dapat dilihat pada tabel 5.

Tabel 5.

Perbedaan Tipe Faking terhadap Pelamar Fresh Graduate dan Berpengalaman pada Wawancara Kerja

\begin{tabular}{lccccc}
\hline & f & Sig. & T & Df & $\begin{array}{c}\text { Sig.(2- } \\
\text { tailed) }\end{array}$ \\
\hline $\begin{array}{c}\text { Equal variances } \\
\text { assumed }\end{array}$ & .130 & .719 & -1.550 & 256 & .122 \\
\hline $\begin{array}{c}\text { Equal variances } \\
\text { not assumed }\end{array}$ & & & -1.475 & 97.212 & .143 \\
\hline
\end{tabular}

Berdasarkan hasil analisa data T-test yang ditunjukkan pada tabel 4 diperoleh nilai T-hitung $(-1,550)<\mathrm{t}$-tabel $(1,969)$ dengan taraf signifikansi $0,719>0,05$. Selanjutnya nilai F-hitung $(0,130)<$ F-tabel $(1,366)$ sehingga dapat disimpulkan bahwa tidak ada perbedaan tipe faking pada pelamar freshgraduate dan pelamar berpengalaman dalam wawancara kerja.

Perilaku faking dalam wawancara kerja kerap dilakukan oleh pelamar agar dinilai baik oleh pewawancara. Lester, Anglim, \& Fullarton (2015) mengungkapkan bahwa pelamar yang berpengalaman biasanya melakukan perilaku faking dengan memberikan klaim bahwa telah melakukan pekerjaan tertentu pada jabatan sebelumnya meskipun hal tersebut tidak pernah dilakukan. Sementara pelamar fresh graduate mungkin perlu menggunakan lebih banyak strategi untuk meningkatkan citra mereka dalam mengimbangi pengalaman yang masih kurang.

Hasil penelitian ini dapat dikatakan mendukung penelitian terdahulu yang menyatakan bahwa dimana gambaran tipe faking dalam wawancara kerja berdasarkan pengalaman kerja menunjukkan bahwa tidak ada perbedaan yang signifikan antara pelamar dengan pengalaman kerja selama 0 (nol) tahun dengan 1 tahun (Akmal et al., 2020).

Perilaku yang ditunjukkan pada tiap tipe faking berbeda-beda. Hogue, Levashina, \& Hang (2013) mengungkapkan ketika pelamar menunjukkan perilaku Slight Image Creation (SIC) saat wawancara berlangsung, pelamar cenderung sedikit meningkatkan 
citra mereka dengan mendistorsi pengalaman kerja sebelumnya agar dapat menyesuaikan antara tujuan pribadi dan tujuan organisasi. Pada Perilaku Ingratiation (I), pelamar umumnya menunjukkan perilaku faking dengan mendukung pernyataan interviewer, meskipun pernyataan tersebut sedikit berbeda dari kebenarannya untuk menyanjung interviewer atau menyesuaikan dengan tujuan organisasi, misalnya pelamar mengungkapkan pendapat yang sama dengan pewawancara atau menertawakan lelucon pewawancara meskipun hal tersebut tidak tampak lucu. Pada perilaku Extensive Image Creation (EIC), pelamar cenderung menceritakan kisah fiksi mengenai pengalaman kerja mereka, sedangkan pada perilaku Image Protection (IP), pelamar umumnya sengaja menutup diri dan menghilangkan informasi penting mengenai pengalaman kerja mereka, seperti kelemahan mereka.

Kemudian, penelitian (Akmal et al. 2021) dilanjutkan dengan menggunakan metode kualitatif dengan pendekatan studi kasus pada 5 subjek penelitian yang memiliki pengalaman kurang dari satu tahun. Dan hasil penelitian menunjukkan bahwa pelamar cenderung menunjukkan perilaku faking dengan mengutamakan penampilan fisik, kemampuan saat berkomunikasi, serta menutupi citra negatif diri saat wawancara kerja berlangsung.

Perbedaan latar belakang keluarga dan pendidikan dapat menjadi penentu mengapa masing-masing subjek memiliki cara masing-masing dalam pengambilan keputusan untuk melakukan perilaku faking saat interview. Hal ini juga disetujui oleh pernyataan Arroba (1998) bahwa tingkat pendidikan merupakan salah satu faktor dalam pengambilan keputusan. Begitu pula dengan pendapat Kotler (2003) bahwa faktor sosial (kelompok acuan, keluarga, peran, dan status) dapat menjadi faktor dalam mengambil keputusan (dalam Akmal et al., 2021). Tidak hanya itu, faktor disposisional, sifat berhati-hati, neourotisme, dan self-monitoring dikaitkan dengan niat yang lebih besar untuk memalsukan wawancara kerja (Lester et al., 2015). Sehingga, sulit bagi interviewer untuk memberikan penilaian secara objektif kepada pelamar. Impression Management (IM) atau manajemen kesan sering digunakan oleh pelamar saat melakukan wawancara kerja. Menurut Law, Bourdage, \& O’Neill (2016) Strategi IM (Impression Management) adalah strategi khusus yang digunakan oleh pelamar untuk memanipulasi citra yang mereka proyeksikan kepada orang lain. Mereka juga mengungkapkan bahwa kerelaan dan kesanggupan pelamar meningkatkan keinginan untuk melakukan perilaku faking karena ingin menunjukkan kesan yang jujur dan rendah hati.

Roulin, Bangerter, \& Levashina (2015) mengungkapkan bahwa sulit untuk mendeteksi faking dalam wawancara. Hal ini dibuktikan bahwa interviewer mendeteksi IM dengan benar rata-rata antara 12\% dan 19\% serta taktik penipuan yang digunakan oleh pelamar (dan antara $13 \%$ dan 25\% dari semua jenis taktik IM). Melalui sebuah penelitian di lapangan, hasil menunjukkan bahwa persepsi interviewer tentang taktik yang digunakan oleh pelamar gagal untuk menyatu dengan taktik yang sebenarnya dilaporkan oleh pelamar. Dengan kata lain, interviewer tidak tahu seberapa jujur atau menipu pelamar selama wawancara (Roulin, 2015). 
Perilaku faking merupakan sesuatu hal yang normal dilakukan dalam kegiatan wawancara kerja. Namun apabila perilaku faking tersebut semakin sering dilakukan hingga membentuk citra diri secara ekstensif, maka perilaku faking tersebut masuk dalam kategori faking negatif atau tidak wajar karena ketika wawancara kandidat sudah menciptakan jawabannya sendiri (El Akmal et al., 2020).

Namun, perilaku faking yang dilakukan oleh pelamar saat wawancara kerja berlangsung tersebut dapat dikurangi dengan memberikan peringatan pada saat sebelum wawancara dimulai. Menurut Law, Bourdage, \& O’Neill (2016) memberikan peringatan pemalsuan khususnya, peringatan identifikasi, dapat mengurangi kapasitas pelamar untuk melakukan perilaku faking saat wawancara berlangsung. Selain itu, peringatan ini juga dapat mengurangi faking tanpa memberi dampak buruk pada reaksi pelamar.

\section{SIMPULAN}

Hasil penelitian menyimpulkan bahwa tidak ada perbedaan tipe faking pada pelamar freshgraduate dan pelamar berpengalaman dalam wawancara kerja berdasarkan hasil analisis data nilai T-hitung $(-1,550)<$ T-tabel $(1,969)$ dengan taraf signifikansi $0,719>$ 0,05 , serta nilai F-hitung $(0,130)<$ F-tabel $(1,366)$. Tipe faking yang paling sering ditampilkan saat wawancara kerja baik oleh pelamar fresh graduate maupun berpengalaman adalah Image Protection (IP), dimana para pelamar umumnya sengaja menutup diri dan menghilangkan informasi penting (kelemahan) mengenai pengalaman kerja mereka.

Saran untuk interviewer adalah agar tetap waspada dan berhati-hati saat mengevaluasi pelamar agar diperoleh kesimpulan yang tepat dan obyektif. Sebelum sesi wawancara dimulai, ada baiknya interviewer mendorong kandidat untuk memberikan informasi yang sebenarnya dan tidak berbohong selama sesi wawancara berlangsung, sehingga data diperoleh dapat sesuai dengan gambaran kandidat yang sesungguhnya.

Bagi para pelamar yang sedang menjalani proses seleksi kerja agar tidak melakukan perilaku faking yang negatif mengenai keterampilan dan pengalaman pelamar, agar hal tersebut tidak mempengaruhi pelamar dalam mengembangkan diri nantinya di perusahaan tempatnya bekerja. Terakhir, untuk penelitian selanjutnya yang akan meneliti tentang faking interview, agar dapat meneliti variabel ini dengan metode, variabel dan karakteristik yang berbeda.

\section{UCAPAN TERIMA KASIH}

Penelitian ini dapat terlaksana dengan adanya bantuan dari berbagai pihak. Karena hal itu, peneliti ingin mengucapkan terima kasih kepada Kementerian Pendidikan Kebudayaan, Riset, Dan Teknologi Direktorat Jenderal Pendidikan Tinggi, Riset, Dan Teknologi sebagai pendana dalam hibah Penelitian Dosen Pemula (PDP) tahun 2020; Rektor Universitas Prima Indonesia, Ketua LPPM Universitas Prima Indonesia, Dekan Fakultas Psikologi Universitas Prima Indonesia, Ketua Program Studi Psikologi Universitas Prima Indonesia atas dukungan dan kesempatan yang diberikan; Manajemen 
Mukhaira El Akmal \& Diny Atrizka, Perbedaan Tipe Faking

Antara Pelamar Fresh Graduate dengan Berpengalaman pada Wawancara Kerja

PT Ariffa Sinergi Prima dan pihak-pihak yang membantu dengan fasilitas dan dukungan selama penelitian ini berlangsung.

\section{DAFTAR PUSTAKA}

Akmal, M.E., Sirait, C., Sinaga, T.A., Ulina, F., Restiani, D., Sari N. (2020) Gambaran perilaku faking pada kegiatan wawancara kerja. Jurnal Psikologi: Media Ilmiah Psikologi 18(1), 20-29. https://doi.org/10.47007/jpsi.v18io1.75

Akmal, M.E., Waruwu, M.D.K.R., Sinaga, Y.C., Alisya, J., Naween. (2021). Self awareness dan perilaku faking pada kegiatan wawancara kerja karyawan. Psyche 165 Journal 14(1), 45-52. https://doi.org/10.35134/jpsy165.v14i1.91

Arroba, T. (1998). Decision making by chinese-us. Journal of Social Psychology, 38, 102-116

Bloomfield, Schofield, A., \& Cantesbury, M. (2006). Panduan rekrutmen: dari penentuan kualifikasi, pengiklanan, interview, evaluasi sampai orientasi. Jakarta: Prestasi Pustaka

Garaika \& Margahana, H. (2019). Peran seleksi (selection) tenaga kerja yang tepat terhadap tercapainya tujuan organisasi. Jurnal Aktual STIE Trisna Negara 17 (2), 133-141, DOI: 10.47232/aktual.v17i2.42

Hamali, A.Y. (2018). Pemahaman Manajemen Sumber Daya Manusia (Strategi Mengelola Karyawan). Yogyakarta: CAPS (Center for Academic Publishing Service)

Hogue, M., Levashina, J., \& Hang, H. (2013). Will i fake it? the interplay of gender, machiavellianism, and self-monitoring on strategies for honesty in job interviews. J Bus Ethics 117, 399-411. https://doi.org/10.1007/s10551-012-1525-X

Kiefer, C., \& Benit, N. (2016). What is applicant faking behavior? A review on the current state of theory and modeling techniques. Journal of European Psychology Student, 7(1), 9-19. http://dx.doi.org/10.5334/jeps.345

Kotler, P. (2003). Marketing Management. Edisi Kesebelas. Upper Saddle River: Prentice-Hall

Law, S. J., Bourdage, J., \& O’Neill, T. A. (2016). To fake or not to fake: Antecedents to interview faking, warning instructions, and its impact on applicant reactions. Journal Frontiers in Psychology, 7:1771. DOI: 10.3389 /fpsyg.2016.01771

Lester, C., Anglim, J., \& Fullarton, C. (2015). Individual Differences in Intention to Fake Job Interviews: Personality, Self-Monitoring, and the Theory of Planned Behaviour. Australasian Journal of Organisational Psychology, 8, E8. DOI:10.1017/orp.2015.7

Levashina, J., \& Campion, M.A. (2007). Measuring Faking in Employment Interview: Development \& Validation of an Interview Faking Behavior Scale. Journal of Applied Psychology. DOI: 10.1037/oo219010.92.6.1638

Pita, M. D. (2011). An integrated model of attitude theory and applicant faking behavior. Disertasi Dipublikasikan. Florida: Florida Institute of Technology

Reddy, Chitra. (9 Maret 2016). Why interviews are important in recruitment process?. Wisestep. Diakses dari https://content.wisestep.com/interviews-important-recruitment-process/

Rivai, V., \& Sagala, E.J. (2013). Manajemen Sumber Daya Manusia untuk Perusahaan: Dari Teori ke Praktik. Edisi Kedua. Cetakan Kelima. Depok: PT. Rajagrafindo Persada

Roulin, N., Bangerter, A., \& Levashina, J. (2015). Honest and deceptive impression management in the employment interview: Can it be detected and how does it impact evaluations?. Personnel Psychology, 68(2), 395-444. https://doi.org/10.1111/peps.12079

Stewart, C.J., \& Cash, W.B. (2003). Interviewing: principles and practices. New York: Mc Graw Hill

Sugiyono. (2016). Statistika untuk Penelitian. Bandung: Alfabeta

Sunyoto, D. (2012). Manajemen Sumber Daya Manusia. Yogyakarta: CAPS (Center for Academic Publishing Service)

Yu, J.(2008). A process model of applicant faking on overt integrity tests. Disertasi Dipublikasikan. Texas: Texas A\&M University 